\title{
Glutathione S-transferases (GSTTI and GSTMI) gene deletions in Tunisians: susceptibility and prognostic implications in breast carcinoma
}

\author{
A Khedhaier', S Remadi ${ }^{1,2}$, M Corbex ${ }^{3}$, SB Ahmed ${ }^{4}$, N Bouaouina ${ }^{1,5}$, S Mestiri', R Azaiez ${ }^{6}$, AN Helal ${ }^{7}$ and \\ L Chouchane*,I
}

'Laboratoire d'immuno-oncologie moléculaire, Faculté de Médecine de Monastir, 5019 Monastir, Tunisia; ${ }^{2}$ Laboratoire Cytopath, Sousse Tunisia; ${ }^{3}$ Centre International de Recherche sur le Cancer (CIRC), Unité d'Epidémiologie Génétique du cancer, Lyon, France; ${ }^{4}$ Service de carcinologie médicale, CHU Farhat Hached, Sousse, Tunisia; ${ }^{5}$ Service de carcinologie radiothérapie, CHU Farhat Hached, Sousse, Tunisia; ${ }^{6}$ Laboratoire de biologie clinique, CHU Fattouma Bourguiba Monastir, Tunisia; ${ }^{7}$ Institut Supérieur de Biotechnologie de Monastir, Monastir, Tunisia

Glutathione S-transferase Thetal and MuI (GSTTI and GSTMI) are involved in the metabolism and detoxification of a wide range of potential environmental carcinogens. Conversely, they contribute to tumour cell survival by detoxification of numerous products induced by cancer therapy. The authors designed a large study to investigate the susceptibility and prognostic implications of the GSTTI and GSTMI gene deletions in breast carcinoma. The authors used the polymerase chain reaction to characterise the variation of the GSTTI and GSTMI genes in 309 unrelated Tunisian patients with breast carcinoma and 242 healthy control subjects. Associations of the clinic-pathologic parameters and the genetic markers with the rates of the breast carcinoma specific overall survival (OVS) and the disease-free survival (DFS) were assessed using univariate and multivariate analyses. A significant association was found between gene deletion of GSTTI and the risk of early onset of breast carcinoma $(O R=1.60, P=0.02)$. The lack of GSTTI gene deletion was significantly associated with poor clinical response to chemotherapy $(O R=2.29, P=0.03)$. This association was significantly higher in patients with axillary's lymph node-negative breast carcinoma $(O R=12.60, P=0.005)$. The null-GSTTI genotype showed a significant association with increased DFS in this selected population of patients. This association was even higher in patients carrying both null-GSTTI and -GSTMI genotypes. The gene deletion of GSTs may predict not only the early onset of breast carcinoma but also the clinical response to chemotherapy and the recurrence-free survival for patients with lymph nodenegative breast carcinoma.

British Journal of Cancer (2003) 89, I502- 1507. doi:I0.I038/sj.bjc.660I292 www.bjcancer.com

(C) 2003 Cancer Research UK

Keywords: GSTTI; GSTMI; polymorphism; breast carcinoma; susceptibility; prognosis

Breast carcinoma is the most frequent malignancy among women, representing a major health problem in many countries. Family history of breast carcinoma and reproductive history account for only 30\% of cases (Henderson, 1993; Ghadirian et al, 1998). Epidemiological studies have suggested that environmental factors may play a major role in the development of breast carcinoma (Haris et al, 1992; Henderson, 1993). The potent carcinogens implicated in breast carcinogenesis are polycyclic aromatic hydrocarbons (PAHs), aromatic and heterocyclic amines present in the diet and environmental exposures (Calaf and Russo, 1993; Dunnick et al, 1995). These were shown to cause mammary tumours in rodents and to form adducts in human breast cells (Cavalieri et al, 1988; Byers, 1994; Dunnick et al, 1995; Pfau et al, 1998). Polycyclic aromatic hydro-carbons are activated by cytochrome P-4501A1(CYP1A1), and the resulting reactive intermediates are detoxified by glutatione-S-transferases (GSTs). These enzymes are expressed in normal breast tissue as well as in breast

*Correspondence: Dr L Chouchane; E-mail: lotfi.chouchane@planet.tn Received 7 April 2003; revised 10 July 2003; accepted 24 July 2003 tumours (Sadreih et al, 1996; Lee et al, 1997; Stone et al, 1998). Individuals who are homozygous for the null-GSTM1 or nullGSTT1 genotypes lack the respective enzyme functions (Seidegaard et al, 1986; Pemble et al, 1994). The null-GSTM1 genotype appears to be common in several populations, whereas the nullGSTT1 genotype exhibits population frequencies that depend on ethnicity (Bell et al, 1993; Nelson et al, 1995; Lin et al, 1998). The GSTM1 and GSTT1 defects seem to be associated with increased risk of certain cancers (Rebbeck, 1997; Strange et al, 1998); however, conflicting data have been observed (Chen et al, 1996; Baily et al, 1998; Houston, 1999). This may be attributable to differences in study design and the analysed populations, as well as to the presence of different confounding factors. The Tunisian population is known for its relative homogeneity. We analysed the relationship between gene deletion of GSTM1 and GSTT1 and the susceptibility to breast carcinoma in this population. Chemotherapy and radiation therapy after surgery for breast carcinoma reduce the risk of recurrence and mortality. However, many patients are not cured with these treatments. Considerable research has been focused on tumour clinic-pathologic characteristics that may predict prognosis. Little is known about the 
possible underlying host factors that could play a substantial role in reduced treatment efficacy. Both chemotherapy and radiation therapy largely exert their antineoplastic effects by generating reactive oxygen products (Hellman, 1993; Weijl et al, 1997). As these are the proximate cause of tumour cell death in many cases, the amounts of reactive species that reach tumour cells and have either direct cytotoxic effects or trigger intracellular apoptotic pathways is likely to have initial and immediate impact on treatment efficacy. Thus, interindividual variability in enzymes that will affect reactive oxygen species (ROS) may have a significant impact on patient prognosis after treatment.

Several reports highlighted the role of GSTs enzymes in the detoxification of numerous products induced by cancer therapy (Hurst et al, 1998; Hayes and Melellan, 1999). GSTT1 and GSTM1 are active in the elimination of several products resulting from reactive oxidant damage to DNA and lipids, such as organic epoxides, and hydroperoxides. The reduction of these molecules by GSTs prevents further oxidant damage within cells. Individuals lacking each of these enzymes may have reduced removal of secondary organic oxidation products produced by cancer therapy and, thus, may have better prognoses. In line with this hypothesis, we investigated, in a large cohort of 309 breast carcinoma from whom complete follow-up data were collected, the potential association of the gene deletion of GSTM1 and GSTT1 enzymes with tumour clinic-pathologic characteristics and with the increased risk of relapse and death from breast carcinoma.

\section{MATERIALS AND METHODS}

\section{Patients and controls}

The gene and allele frequencies of the GSTT1 and GSTM1 genes were determined in a group of 242 control subjects and 309 patients with breast carcinoma. Controls and patients were selected from the same population living in the middle coast of Tunisia. Both the control and patients groups include unrelated subjects.

Clinical follow-up data were collected on the cohort of the 309 patients recruited from the department of Radiation Oncology and Medical Oncology of Sousse Hospital (Sousse Tunisia) between 1994 and 2002.

All patients included in this study had primary breast carcinoma, with unilateral breast tumours. The patients (304 females and five males) had a mean age of $52 \pm 24$ years. The median of follow-up was 36 months (range, 1-120 months). At time of analysis, 76 patients relapsed (local or distant recurrence). Among them, 36 patients died from breast carcinoma (47.3\%). A detailed description of the clinic-pathologic characteristics of this cohort has been reported elsewhere (Ben Ahmed et al, 2002).

Control subjects (110 females and 132 males) having a mean age of $41 \pm 14$ years, were healthy blood donors having no evidence of any personal or family history of cancer (or other serious illness). Written informed consent was obtained from all subjects.

\section{Patients treated by chemotherapy as a primary treatment:}

Among the 309 patients, 140 had chemotherapy as an anticancer primary treatment. This group includes 122 patients who had neoadjuvant chemotherapy and 18 patients who received chemotherapy as a palliative treatment. The chemotherapy induction was based in all cases on the combination of cyclophosphamide $(100 \%), 5$-fluorouracil $(100 \%)$ with adriamycin (36\%) or epirubicin $(51 \%)$ or methotrexate $(13 \%)$. For neoadjuvant treatment, patients received four or six chemotherapy cycles before surgery. The clinical response to induction chemotherapy for all cases was defined according to the following criteria: complete response when regression of the tumour was total, partial response when the reduction of tumour size was greater than $50 \%$ and poor response when the reduction of tumour size was less than $50 \%$ (tumour size was measured by the bidimensional product of the horizontal and vertical dimensions). Lumpectomy or mastectomy was performed 3 weeks after the last cycle of induction chemotherapy; postoperatively, patients resumed chemotherapy. Consolidative radiation therapy was performed in 26 cases.

\section{DNA extraction}

Genomic DNA was extracted from peripheral blood leucocytes by a salting out procedure (Olerup and Zetterquist, 1992). Briefly, $10 \mathrm{ml}$ of blood was mixed with triton lysis buffer. Leucocytes were spun down and washed with $\mathrm{H}_{2} \mathrm{O}$. The pellet was incubated with proteinase $\mathrm{K}$ at $56^{\circ} \mathrm{C}$ and subsequently salted out at $4{ }^{\circ} \mathrm{C}$ using a saturated $\mathrm{NaCl}$ solution. Precipitated proteins were removed by centrifugation. The DNA in the supernatant was precipitated with ethanol. The DNA pellet was dissolved in $400 \mu \mathrm{l}$ sterile distilled $\mathrm{H}_{2} \mathrm{O}$.

\section{Polymorphism analysis of GSTT1 and GSTM1 genes}

Polymorphic deletion of the GSTT1 and GSTM1 genes was revealed by PCR-based assays with $\beta$-interferon as a control gene.

In addition to the $\beta$-interferon primers ( $5^{\prime}$-GGCACAACAGGTAGTAGGCG- $3^{\prime}$, and $5^{\prime}$-GCCACAGGAGCTTCTGACAC- $3^{\prime}$ ), two sequence specific oligonucleotide primers (GSTT1 or GSTM1) were used for each PCR: for GSTT1, the $3^{\prime}$ primer (5'-TTCCTTACT GGTCCTCACATCTC- $3^{\prime}$ ) was used in combination with the $5^{\prime}$ primer $\left(5^{\prime}\right.$-TCACCGGAT CATGGCCAGCA-3'). For GSTM1, the $3^{\prime}$ primer ( $5^{\prime}$-CTGCCCTACTTG ATTGATGGG-3') was used with the $5^{\prime}$ primer (5'-CTGGATTGTAGCAGATCATGC-3'). In all, $30 \mu \mathrm{l}$ of PCR reaction mixture was comprised of genomic DNA samples (100 ng), $200 \mu \mathrm{moll}^{-1}$ dNTPs, $1.5 \mathrm{mM} \mathrm{MgCl}_{2}, 1 \times$ Taq polymerase buffer, $100 \mathrm{pmol}$ of each primer and $0.5 \mathrm{U}$ of Taq DNA polymerase (Amersham, Paris, France). The reaction conditions used with the thermal cycler (Biometra, Göttingem, Germany) were as follows: for GSTT1, the initial incubation at $94^{\circ} \mathrm{C}$ for $4 \mathrm{~min}$, followed by 30 cycles of incubation at $94^{\circ} \mathrm{C}$ for $1 \mathrm{~min} ; 66^{\circ} \mathrm{C}$ for $1 \mathrm{~min}$, and $72^{\circ} \mathrm{C}$ for $1 \mathrm{~min}$ and followed by a final incubation at $72^{\circ} \mathrm{C}$ for $5 \mathrm{~min}$. For GSTM1, the initial incubation at $94^{\circ} \mathrm{C}$ for $5 \mathrm{~min}$, followed by 30 cycles of incubation at $94^{\circ} \mathrm{C}$ for $30 \mathrm{~s} ; 60^{\circ} \mathrm{C}$ for $1 \mathrm{~min}$, and $72^{\circ} \mathrm{C}$ for $1 \mathrm{~min}$ and followed by a final incubation at $72^{\circ} \mathrm{C}$ for $5 \mathrm{~min}$.

The reaction products were separated on a $2 \%$ agarose gel and stained with ethidium bromide. The absence of amplified GSTT1 $(480 \mathrm{bp})$ or GSTM1 $(271 \mathrm{bp})$ product (in the presence of the interferon PCR product $(170 \mathrm{bp})$ indicated the respective null genotype for each.

\section{Statistical analyses}

The $\chi^{2}$ test was used to evaluate for a significant association between disease (breast carcinoma $v s$ controls) and GSTT1 or GSTM1 genotypes.

Disease-free survival (DFS) was defined as the time from the date of diagnosis to the first local or distant recurrence or to last contact. Breast carcinoma-specific overall survival (OVS) was defined as the time from the date of diagnosis to death if the patient died from breast carcinoma or to last contact. Six-year survival rates were estimated, and survival curves were plotted according to Kaplan and Meier (1958). The differences between groups were calculated by the log-rank test (Peto et al, 1977).

Clinicopathological parameters were dichotomised as follows: nodal status ( $\geqslant 1$ vs no positive lymph node), SBR (Scarff, Bloom and Richardson) tumour grade (1-2 vs 3), clinical tumour size $\left(\mathrm{T}_{1}-\mathrm{T}_{2}\right.$ vs $\left.\mathrm{T}_{3}-\mathrm{T}_{4}\right)$.

Statistics were performed using SEM-STATISTIQUES software (Centre Jean Perrin, Clermont-Ferrand, France). 


\section{RESULTS}

\section{Polymorphisms in GSTT1 and GSTM1 genes and breast carcinoma}

The distribution of the GSTT1 and GSTM1 genotypes in the patient and in the control groups is shown in Table 1. The frequency of the null-GSTT1 genotype was 0.333 in the group of patients with breast carcinoma and 0.260 in control subjects $(\mathrm{OR}=1.42, P=0.06)$. No significant differences in null-GSTM1 distributions were seen between patients and controls $(\mathrm{OR}=0.87, P>0.05)$. The frequency of the double null-GSTT1-GSTM1 was slightly higher in patients (0.178 vs $0.149, \mathrm{OR}=1.24)$, but the difference did not reach statistical significance. When we stratified the patients according to their menopause status, we found that the null-GSTT1 genotype frequency was significantly higher in premenopausal patients than in controls $(0.360$ vs $0.260, \mathrm{OR}=1.60, P=0.02)$. Thus, there was an association between the presence of the null-GSTT1 genotype and the early onset of breast carcinoma. None of the GSTM1 genotypes, either alone or in combination with GSTT1 genotypes, was associated with breast carcinoma in the different subgroups.

\section{Prognostic significance of polymorphisms in GSTT1 and GSTM1 genes}

Among the 309 patients with breast carcinoma, 140 had chemotherapy as an anticancer primary treatment, including 122 patients treated by neoadjuvant chemotherapy. A total of 53 patients were axillary's lymph node-negative. Table 2 shows the associations between gene deletion of GSTT1 and GSTM1 and the clinical response to chemotherapy induction. Poor response to chemotherapy was seen significantly more frequently in patients having the 'present'-GSTT1 genotype compared to those carrying the null-GSTT1 genotype $(\mathrm{OR}=2.29, P=0.03)$. This association seems to be particularly high for patients who were node-negative $(\mathrm{OR}=12.60, P=0.005)$. Poor response to chemotherapy was seen slightly more frequently in patients carrying the 'present'-GSTM1 genotype than those with the null-GSTM1 genotype, but without reaching statistical significance (0.516 vs $0.483, P=0.19)$.

We were interested in the combined effects that null genotype for both GSTM1 and GSTT1 may have had on the clinical response to chemotherapy. Poor response to chemotherapy was significantly less frequent in patients carrying the double-dose null-GSTT1GSTM1 genotype than in patients without $(\mathrm{OR}=2.97, P=0.04)$. No patient who was node-negative and carrying the double nullGSTT1-GSTM1 genotypes had poor response to chemotherapy. In contrast, 19 patients, among 45 lacking the double null genotypes had poor clinical response $(P=0.02)$.

Table 3 shows the clinicopathological characterisation. The distribution of the clinicopathological markers was in agreement with previously reported data, indicating that our cohort (309 patients) was representative of breast carcinoma patients. Diseasefree survival and breast carcinoma-specific OVS rates were estimated and compared by univariate analysis on these clinico-

Table I GSTTI and GSTMI genotype frequencies in control subjects and in patients with breast carcinoma

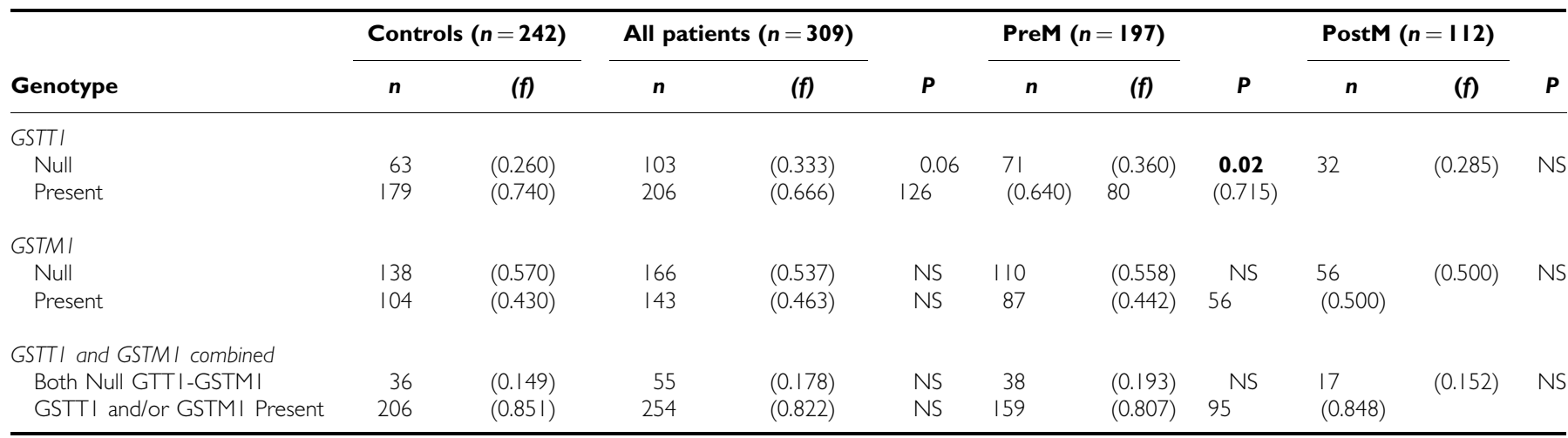

The $\chi^{2}$ test was used to determine whether significant differences ( $P$-value) were observed when the patient group was compared with the control group. PreM = premenopausal patients; PostM = postmenopausal patients; f, frequencies; NS: not significant.

Table 2 Associations between GSTTI and GSTMI genetic deletions and clinical response to chemotherapy induction

\begin{tabular}{|c|c|c|c|c|c|c|c|c|c|c|}
\hline \multirow{3}{*}{ Genotype } & \multicolumn{9}{|c|}{ Chemotherapy response } & \\
\hline & \multicolumn{2}{|c|}{ Poor } & \multicolumn{2}{|c|}{ Complete/partial } & \multirow[b]{2}{*}{$P$-value } & \multicolumn{2}{|c|}{ Poor } & \multicolumn{2}{|c|}{ Complete/partial } & \multirow[b]{2}{*}{$P$-value } \\
\hline & $n$ & (f) & $n$ & $(f)$ & & $n$ & $(f)$ & $n$ & $(f)$ & \\
\hline \multicolumn{11}{|l|}{ GSTTI } \\
\hline Null & 13 & $(0.217)$ & 31 & $(0.388)$ & 0.03 & & $(0.052)$ & 14 & $(0.4 \mid 2)$ & 0.005 \\
\hline Present & 47 & $(0.783)$ & 49 & $(0.6 \mid 2)$ & 18 & $(0.948)$ & 20 & $(0.588)$ & & \\
\hline Null & 29 & $(0.483)$ & 47 & $(0.588)$ & NS & & $(0.474)$ & & $(0.589)$ & NS \\
\hline Present & 31 & $(0.516)$ & 33 & $(0.412)$ & 10 & $(0.526)$ & 15 & $(0.44 I)$ & & \\
\hline \multicolumn{11}{|l|}{ GSTTI and GSTMI combined } \\
\hline Both Null GTTI-GSTMI & 05 & $(0.083)$ & 17 & $(0.212)$ & 0.04 & & $(0.000)$ & & $(0.235)$ & $0.02^{\mathrm{a}}$ \\
\hline GSTTI and/or GSTMI Present & 55 & $(0.917)$ & 63 & $(0.788)$ & 19 & $(1.000)$ & 26 & $(0.765)$ & & \\
\hline
\end{tabular}

The $\chi^{2}$ test was used to determine whether significant differences ( $P$-value) in the clinical response to chemotherapy were observed between carriers of different genotypes. NS: not significant; f: frequencies; ALN = axillary's lymph node-negative. ${ }^{a}$ Fisher's test was used. 
Table 3 Clinicopathological characteristics of the 309 breast carcinoma and the corresponding univariate analysis of death (OVS) and relapse (DFS)

\begin{tabular}{|c|c|c|c|c|c|}
\hline & \multirow[b]{2}{*}{$\%$} & \multicolumn{2}{|c|}{ Breast carcinoma-specific OVS } & \multicolumn{2}{|c|}{ DFS } \\
\hline & & 6-year rate & $P$-value & 6-year rate & $P$-value \\
\hline \multicolumn{6}{|c|}{ Clinical tumour size } \\
\hline$T_{1}-T_{2}$ & 62.28 & 86.76 & $<0.03$ & 79.4 & $<0.0001$ \\
\hline$T_{3}-T_{4}$ & 37.72 & 72.05 & 38.2 & & \\
\hline \multicolumn{6}{|c|}{ Lymph node status } \\
\hline $\mathrm{N}(-)$ & 54.2 & 94.11 & $<0.001$ & 76.47 & $<0.01$ \\
\hline$N(+)$ & 45.8 & 69.12 & 57.35 & & \\
\hline \multicolumn{6}{|c|}{ SBR grading } \\
\hline $1-2$ & 61.2 & 87.3 & $<0.01$ & 59.7 & $<0.04$ \\
\hline 3 & 38.8 & 58.3 & 36.1 & & \\
\hline \multicolumn{6}{|c|}{ Age (years) } \\
\hline$<50$ & 60.26 & 80.88 & NS & 73.5 & NS \\
\hline$\geqslant 50$ & 39.74 & 86.76 & 73.5 & & \\
\hline
\end{tabular}

Six-year survival rates were estimated according to Kaplan and Meier (1958). The logrank test (Peto et al, 1977) was used to determine whether significant differences ( $P$ value) were observed between subgroups of patients. The lymph node status was determined based on the pathological examination. NS: not significant.

pathological parameters. Significant associations were found for clinical tumour size, nodal status and tumour grading with DFS and OVS. No significant differences were observed for age.

When we tested the relationship between the presence of nullGSTT1 and/or null-GSTM1 genotypes in all 309 patients and the survival (OVS or DFS), no significant differences were observed between the different Kaplan-Meier survival curves (data not shown).

We conducted further analyses to explore whether the GSTs gene deletion was associated with survival on a selected population of patients. We selected patients with axillary's lymph nodenegative from the total patient population. No significant differences were seen between different OVS curves, indicating lack of association between GSTs gene deletion and OVS in this selected population.

Figure 1 shows the breast carcinoma-specific DFS of breast carcinoma in patients with axillary's lymph node-negative according to the presence or absence of the null-GSTT1 and/or null-GSTM1 genotypes. The DFS was significantly longer in the group of patients carrying the null-GSTT1 genotype (Figure 1A). The estimated 3- and 6-year DFS rates in the groups of patients carrying the 'present'-GSTT1 genotype or carrying the null-GSTT1 genotype were, respectively, 85 and $61 \%$ vs 98 and $83.5 \%$ (log-rank test, $P=0.02$ ).

Although differences in DFS were seen between patients carrying the 'present'-GSTM1 genotype and those with nullGSTM1 genotype, they did not reach statistical significance (Figure $1 \mathrm{~B}$, log-rank test, $P=0.21$ ). When DFS comparison was made between patients who had both 'present'-GSTT1 and GSTM1 genotypes and those with both null-GSTT1-GSTM1 genotypes (Figure 1C), an increase in DFS was seen for patients carrying both null-GSTT1 and GSTM1 genotypes. The 6-year DFS rate in the group of patients with 'present'-GSTT1-GSTM1 genotypes was 65.7 and $87.1 \%$ in that of patients with null-GSTT1-GSTM1 genotypes (log-rank test, $P=0.01$ ).

\section{DISCUSSION}

Several studies have addressed the role of GSTT1 and GSTM1 gene deletions as risk factors in breast carcinoma, but the results are
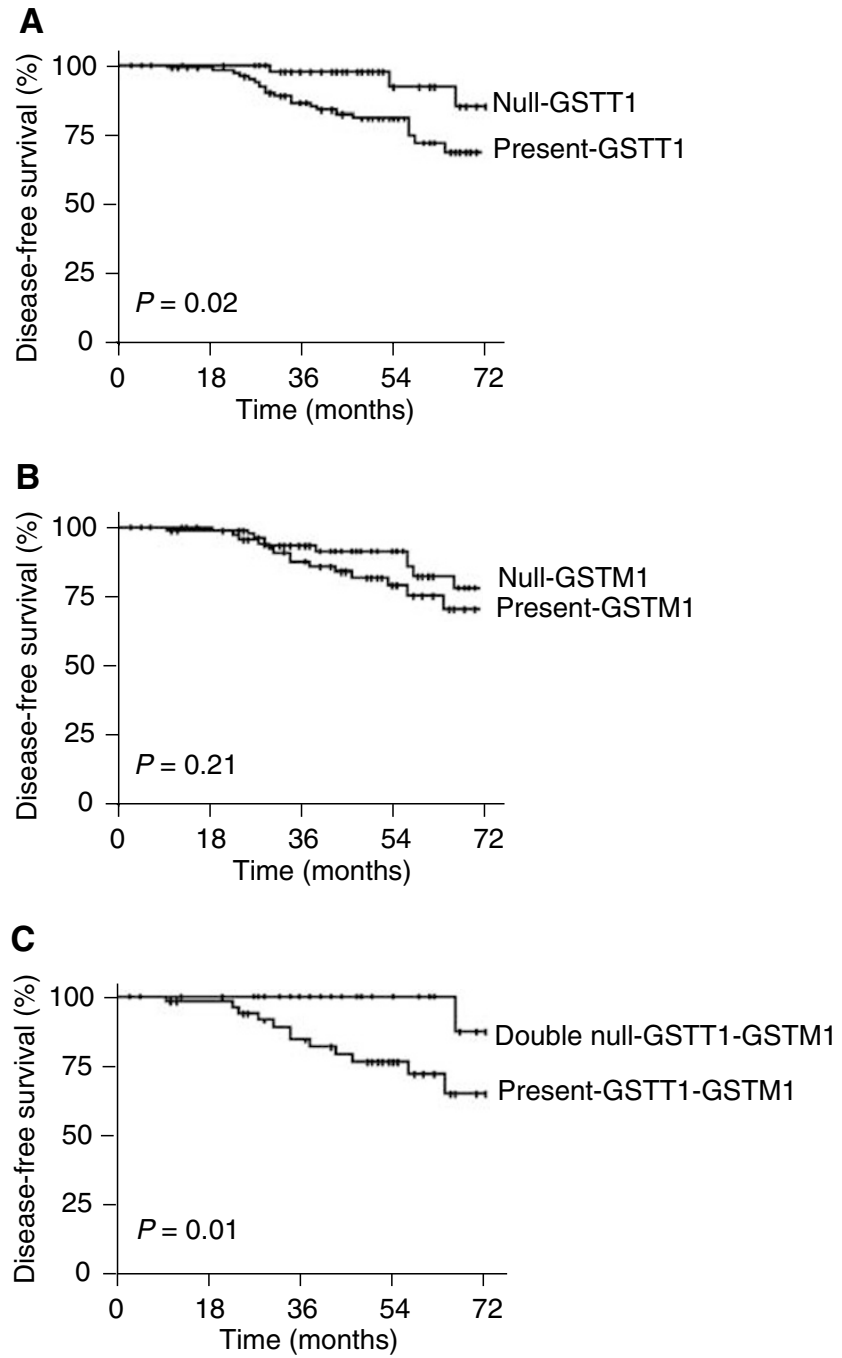

Figure I Breast carcinoma-specific DFS of axillary's lymph node-negative breast carcinoma patients according to the presence or absence of the nullGSTTI genotype (A), that of null-GSTMI genotype $(\mathbf{B})$ and that of the double null-GSTTI-GSTMI genotype $(\mathbf{C})$. $P$ denotes the log-rank test value.

conflicting (Helzlsouer et al, 1998; Gumundsdottir et al, 2001; Krajinovic et al, 2001; Mitrunen et al, 2001). The ethnic heterogeneity of the analysed populations may be among the confounding factors. Hence, in this study, we assessed the potential association of these genetic polymorphisms with breast carcinoma in the Tunisian population, known for its relative homogeneity. The findings, which showed that GSTs enzymes play crucial role in the detoxification of numerous products induced by cancer therapy, prompted us to evaluate the prognostic significance of GSTs deletions in breast carcinoma.

The present case/controlled study showed a borderline significant increase in the risk of breast carcinoma in unselected subjects carrying the null-GSTT1 genotype. This association becomes clearly significant for premenopausal women. Thus the GSTT1 deletion seems to be associated specifically with the early onset of breast carcinoma. No direct correlation was found between polymorphism in the GSTM1 gene and the breast carcinoma onset in Tunisians. Our data provide evidence against a substantially increased risk of breast carcinoma associated with GSTM1 homozygous gene deletion. 
The generation of ROS and their byproducts is a large part of the cytotoxic activity of chemotherapy agents. Several studies have shown that patients treated with a wide range of chemotherapy agents have marked increases in lipid peroxidation products (Subramaniam et al, 1993; Look and Musch, 1994; Faber et al, 1995; Faure et al, 1996). All patients of this study were treated primarily with cyclophosphamide and 5-flurouracil. There is evidence that these agents, particularly cyclophosphamide, result in lipid peroxidation and generation of ROS. The mechanism by which cyclophosphamide kills tumour cell through ROS is demonstrated by rodent data showing that the lung injury associated with treatment with cyclophosphamide is attributable to its ability to generate free radicals (Patel, 1990; Venkatesan and Chandrakasan, 1995). The GSTT1 and GSTM1 enzymes have been shown to have removal activity toward lipid hydroperoxides. The lack of these enzymes could conceivably be associated with better response to chemotherapy. In this study, we initiate the prognostic significance evaluation of the GSTs deletions by investigating the potential association between GSTT1 and GSTM1 gene deletion and the clinical response to chemotherapy induction. This evaluation indicated that only GSTT1 gene deletion is associated with the clinical response to chemotherapy. This prognostic significance was particularly high for patients with axillary's lymph node-negative breast carcinoma. Although no significant association was found between GSTM1 gene deletion and the response to chemotherapy, a combined effect of GSTT1 and GSTM1 gene deletions was seen on the response to chemotherapy induction. Indeed, none of the patients with lymph node-negative and carrying the double null-GSTT1-GSTM1 genotype had poor response to chemotherapy. In studies of haematopoietic cancers, reduced risk of disease recurrence was noted among children with acute lymphoblastic leukaemia, who had alleles encoding no or lower activity for GSTT1, -M1 and -P1 (Stanulla et al, 2000). An increased therapy-related toxicity among the GSTT1-null patients with acute myelocytic leukaemia has been shown (Davies et al, 1999). These findings support the hypothesis that patients with
GSTT1-null genotypes have reduced detoxification of therapeutic agents and, in the case of high-dose therapy for acute myelocytic leukaemia, worse outcomes. In the present study of primary breast carcinoma patients, the better response to chemotherapy that was observed among GSTT1-null patients, who were not treated with high-dose therapy, can be explained by the increased efficacy of treatment.

There have been only a few studies of GST genetic polymorphism and survival after treatment of breast carcinoma (Lizard-Nacol et al, 1999; Ambrosone et al, 2001). For the most part, prior studies were undertaken on a small or heterogeneous population. In our data, the effect of GSTT1 and GSTM1 gene deletions on survival after the treatment of breast carcinoma was not evident in the entire population. The selection of axillary's lymph node-negative breast carcinoma allowed the appearance of a significant association between DFS of breast carcinoma and the GSTT1 gene deletion. No association was found with the GSTM1 gene deletion. However, there was an increase in DFS for patients carrying both gene deletions for GSTT1 and GSTM1.

In conclusion, this study suggests that GSTT1 gene deletion may be an attractive susceptibility marker for the early onset of breast carcinoma. This genetic marker represents not only a predictor of chemotherapy response but also a prognostic variable for predicting relapse in patients with lymph node-negative breast carcinoma.

\section{ACKNOWLEDGEMENTS}

This work was supported by le Secrétariat d'Etat de la Recherche Scientifique et de Technologie, by le Ministère de l'Enseignement Supérieur, by le Ministère de la Santé Publique de la République tunisienne. We thank Salouha Gabbouj, Elham Hassen and Rayhane Elkares for technical assistance.

\section{REFERENCES}

Ambrosone CB, Sweeney C, Coles BF, Thompson PA, McClure HY, Korourian S, Fares MY, Stone A, Kadlubar FF, Hutchins LF (2001) Polymorphisms in glutatione S-transferases (GSTM1 and GSTT1) and survival after treatment for breast cancer. Cancer Res 61: 7130-7135

Baily LR, Roodi N, Verrier CS, Yee CJ, Dupont WD, Parl FF (1998) Breast cancer and CYP1A1, GSTM1 and GSTT1 polymorphisms evidence of a lack of association in Caucasians and African Americans. Cancer Res 58: $65-70$

Bell DA, Taylor JA, Paulson DF, Mohler JL, Lucier GW (1993) Genetic risk and carcinogen exposure: a common inherited defect of the carcinogenmetabolism gene glutathione S-transferase M1(GSTM1) that increases susceptibility to bladder cancer. J Natl Cancer Inst 85: 1159- 1164

Ben Ahmed S, Aloulou S, Bibi M, Landolsi A, Nouira M, Ben Fatma L, Kallel L, Gharbi O, Korbi S, Khairi H, Kraiem C (2002) Breast cancer detection in Tunisian women: an analysis of a hospital trial involving 729 patients. Santé Publique 14(3): 231-241

Byers T (1994) Nutritional risk factors for breast cancer. Cancer 74: $288-295$

Calaf G, Russo J (1993) Transformation of human breast epithelial cells by chemical carcinogens. Carcinogenesis 14: 483-492

Cavalieri E, Rogan E, Sinha D (1988) Cacinogenicity of aromatic hydrocarbons directly applied to rat mammary gland. J Cancer Res Clin Oncol 114: 3-9

Chen C, Madeleine MM, Lubinski C, Tichman EW, Daling JR (1996) glutathione S-transferase M1 genotypes and the risk of anal cancer: a population-based case-control study. Cancer Epidemiol Biomark Prev 5: 985-991

Davies SM, Buckely JD, Robinson LL, Tjoe T, Woods WG, Radloff GA, Ross JA, Perentesis JP (1999) Glutathione S-transferase polymorphisms and outcome of chemotherapy in childhood AML. Blood 94: S1
Dunnick JK, Elwell MR, Huff J, Barrett JC (1995) Chemically induced mammary gland cancer in the National Toxicology Program's carcinogenesis bioassay. Carcinogenesis 16: 173-179

Faber M, Coudray C, Hida H, Mousseau M, Favier A (1995) Lipid peroxidation products, and vitamin and trace element status in patients with cancer before and after chemotherapy, including adriamycin. A preliminary study. Biol Trace Elem Res 47: 117-123

Faure H, Coudray C, Mousseau M, Ducros V, Douki T, Favier A (1996) 5-Hydroxy -methyluracil excretion. Plasma TBARS and plasma antioxidant vitamins in adriamycin-treated patients. Free Radic Biol Med 20: 979-983

Ghadirian P, Lacroix A, Perret C, Robodoux A, Falardeau M, Maisonneuve $P$ (1998) Breast cancer risk and nutrient intake among French Canadians in Montreal: a case-control study. Breast 7: 108-113

Gumundsdottir K, Tryggvadottir L, Eyfjord JE (2001) GSTM1, GSTT1, and GSTP1 genotypes in relation to breast cancer risk and frequency of mutations in the p53 gene. Cancer Epidemiol Biomarkers Prev 10: $1169-1173$

Haris JR, Lippman ME, Veronesi U, Willett W (1992) Breast cancer (1). $N$ Engl J Med 327: 319-328

Hayes JD, Melellan LI (1999) Glutathione and glutathione-dependent enzymes represent a co-ordinately regulated defence against oxidative stress. Free Radic Res 31: $273-300$

Hellman S (1993) Principles of radiation therapy. In Cancer: Principles and Practice of Oncology, Devita VT, Hellman S, Rosemberg SA (eds), 4th edn, pp 248-275. Philadelphia: J.B. Lippincott Co.

Helzlsouer KJ, Selmin O, Huang HY, Strickland PT, Hoffman S, Alberg AJ, Watson M, Comstock GW, Bell D (1998) Association between glutathione S-transferase M1, P1, and T1 genetic polymorphisms and development of breast cancer. J Natl Cancer Inst 90: 512-580 
Henderson IC (1993) Risk factors for breast cancer development. Cancer 71: $2127-2140$

Houston RS (1999) Glutathione S-transferase M1 Status and lung cancer risk: a meta-analysis. Cancer Epidemiol Biomark Prev 8: 675-682

Hurst R, Bao Y, Jemth P, Mannervik B, Williamson G (1998) Phospholipid hydroperoxide glutathione peroxidase activity of human glutathione transferases. Biochem J 332: $97-100$

Kaplan EL, Meier P (1958) Nonparametric estimation from incomplete observations. J Am Stat Assoc 53: 457-481

Krajinovic M, Ghadirian P, Sinnet H, Gandini S, Perret C, Lacroix A, Labuda D, Sinnet D (2001) Genetic susceptibility to breast cancer in French - Canadians: role of carcinogen-metabolizing enzymes and geneenvironment interaction. Int J Cancer 92: 220-225

Lee JH, Chung JG, Levy GN, Weber ww (1997) Kinetics of arylamine $\mathrm{N}$-acetyltransferase in tissues from human breast cancer. Cancer Lett 111: $39-50$

Lin DX, Tang YM, Peng Q, Ambrosone B, Kadlubar FF (1998) susceptibility to esophageal cancer and genetic polymorphisms in glutathione $\mathrm{S}$ transferase T1, P1 and M1and cytochrome P450 2E1. Cancer Epidemiol Biomark Prev 7: 1013-1018

Lizard-Nacol S, Coudert B, Colosetti P, Riedinger JM, Fargeot P, BrunetLecomte P (1999) Glutathione S-transferase M1 null genotypes: lack of association with tumor characteristics and survival in advanced breast cancer. Breast Cancer Res Treat 81-87

Look MP, Musch E (1994) Lipid peroxides in the polychemotherapy of cancer patients. Chemotherapy 40: 8-15

Mitrunen K, Jourenkova N, Kataja V, Eskelinen M, Kosma VM, Benhamou S, Vainio H, uusitupa M, Hirvonen A (2001) Glutatione S-transferase M1, M3, P1, and T1 genetic polymorphisms and susceptibility to breast cancer. Cancer Epidemiol Biomarkers Prev 10: 229-263

Nelson HH, Wienck JK, Christiani DC, Cheng TJ, Zuo ZF, Wang M, XU XP, Kelsey KT (1995) Ethic differences in the prevalence of the homozygous deleted genotype of glutathione S-transferase $\theta$. Carcinogenesis 16: $1243-1245$

Olerup O, Zetterquist H (1992) HLA-DR typing by PCR amplification with sequence specific primers (PCR-SSP) in 2 hours: an alternative to serological DR typing in clinical practice including donor- recipient matching in cadaveric transplantation. Tissue Antigens 39: 225-235

Patel JM (1990) Metabolism and pulmonary toxicity of cyclophosphamide. Pharmacol Ther 47: 137 - 146
Pemble S, Shroeder KR, Spenser SR, Meyer DJ, Ketterer B, Taylor JB (1994) Human glutathione S-transferase $\theta$ (GSTT1) cDNA cloning and the characterization of a genetic polymorphism. Biochem $J$ 300: $271-276$

Peto R, Pike MC, Armitage P, Breslow NE, Cox DR, Howard SV, Mantel N, McPherson K, Peto J, Smith PG (1977) Design and analysis of randomized clinical trials requiring prolonged observation of each patient. II. Analysis and examples. Br J Cancer 35: 1-39

Pfau W, Stone EM, Brockstedt U, Carmichael PL, Phillips DH (1998) DNA adducts in human breast tissue: association with $\mathrm{N}$-acetyltransferase-2 (NAT2) and NAT1 genotypes. Cancer Epidemiol Biomark Prev 7: $1019-1025$

Rebbeck TR (1997) Molecular epidemiology of the human glutathione S-transferase genotypes GSTM1 and GSTT1 in susceptibility cancer. Cancer Epidemiol Biomark Prev 6: 733-743

Sadreih N, Davis CD, Snyderwine EG (1996) $N$-acetyltransferase expression and metabolic activation of the food-derived heterocyclic amines in the human mammary gland. Cancer Res 56: 2683-2687

Seidegaard J, Pero R, Miller DJ, Beattie EJ (1986) A glutathione transferase in human leukocytes as a marker for the susceptibility to lung cancer. Carcinogenesis 7: $751-753$

Stanulla M, Schrappe M, Brechlin AM, Zimmermann M, Welte K (2000) Polymorphisms within glutathione S-transferase genes (GSTM1, GSTT1, GSTP1) and risk of relapse in childhood B-cell precursor acute lymphoblastic leukemia: a case control-study. Blood 95: 1222-1228

Stone EM, Williams JA, Grover PL, Phillips DH (1998) Interindividual variation in the metabolic activation of heterocyclic amines and their $N$ hydroxy derivatives in primary cultures of human mammary epithelial cells. Carcinogenesis 19: $873-879$

Strange RC, Lear JT, Fryer AA (1998) Glutathione S-transferase polymorphisms: influence on susceptibility to cancer. Chem Biol Interact 111 - 112: 351 - 364

Subramaniam S, Shyama S, Jagadeesan M, Shyamala Devi CS (1993) Oxidant and antioxidant levels in the erythrocytes of breast cancer patients treated with CMF. Med Sci Res 21: 70-80

Venkatesan N, Chandrakasan G (1995) Modulation of cyclophosphamideinduced early lung injury by curcumin, an anti-inflammatory antioxidant. Mol Cell Biochem 142: 79-87

Weijl NI, Cleton FJ, Osanto S (1997) Free radicals and antioxidants in chemotherapy-induced toxicity. Cancer Treat Rev 23: 209-240 